\title{
¿Localidades informales, excedentarias o segregadas? La heterogeneidad urbana en Uruguay según el Censo de 1963
}

Informal, Surplus or Segregated Localities? Urban Heterogeneity in Uruguay According to the 1963 Census

Localidades informais, excedentes ou segregadas?

Heterogeneidade urbana no Uruguai segundo o Censo de 1963

Tabaré Fernández ${ }^{*}$

Andrés Wilkin ${ }^{* *}$

Tania Biramontes ${ }^{* *}$

Recibido: 26 de abril de 2021

Aprobado: 29 de julio de 2021

https://doi.org/10.12804/revistas.urosario.edu.co/territorios/a.10333

Para citar este artículo: Fernández, T., Wilkins, A., \& Biramontes, T. (2022). ¿Localidades informales, excedentarias o segregadas? La heterogeneidad urbana en Uruguay según el Censo de 1963. Territorios, (46), 1-28. https://doi.org/10.12804/revistas.urosario.edu.co/territorios/a.10333

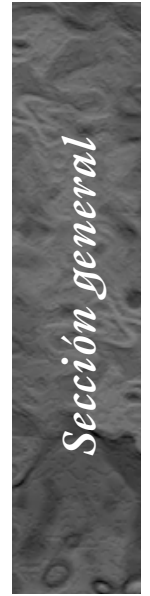

* Doctor en Sociología por el Colegio de México. Departamento de Sociología, Facultad de Ciencias Sociales, Universidad de la República, Uruguay. Correo electrónico: tabare.fernandez@cienciassociales.edu.uy. ORCID: bttps://orcid.org/00000001-5019-7882

** Estudiante avanzado de la Licenciatura en Sociología por la Facultad de Ciencias Sociales, UDELAR, Uruguay. Correo electrónico: andres. wilkins@cienciassociales. edu.uy. ORCID: https:// orcid.org/0000-00020650-124X

*** Magister en Demografía y Estudios de Población por la Facultad de Ciencias Sociales, UDELAR. Departamento de Sociologia, Facultad de Ciencias Sociales, 
Palabras clave

Uruguay; censo 1963; rancherios; modernización rural; segregación urbana.

Keywords

Uruguay; census 1963; rural poverty; rural development; urban segregation.

Palavras-chave

Uruguai; censo 1963; fazendas; modernização rural; segregação urbana.

\section{territarias 46}

\section{RESUMEN}

Con base en el Censo de 1963, el análisis de clúster es utilizado para poner a prueba tres hipótesis que proponían explicar la emergencia de microlocalidades a principios del siglo xx en Uruguay: la informalidad, el excedente rural y la segregación urbana. Los hallazgos son solo parcialmente consistentes con aquellas. Estas localidades serían en forma significativa, un fenómeno de la omisión reguladora del Estado, aunque solo una proporción pequeña puede ser tratada como asiento de la población rural excedentaria y al menos un tercio de las localidades constituirían una expresión de un fenómeno nuevo para la época: la segregación urbana.

\section{ABSTRACT}

Based on the 1963 Census, cluster analysis is used to test three hypotheses that were proposed to explain the emergence of microlocalities in the early twentieth century in Uruguay: informality, rural surplus and urban segregation. The findings are only partially consistent with those. These localities would be significantly a phenomenon of state regulatory omission, although only a small proportion can be treated as a seat of the surplus rural population and at least one-third of the localities would be an expression of a new phenomenon at the time: urban segregation.

\section{RESUMO}

Com base no Censo de 1963, a análise de cluster foi utilizada para testar três hipóteses que se propunham a explicar o surgimento das microlocalidades no início do século xx no Uruguai: informalidade, excedente rural e segregação urbana. Os resultados são apenas parcialmente consistentes com as hipóteses. Essas localidades seriam, de forma significativa, um fenômeno de omissão regulatória do Estado, embora apenas uma pequena proporção possa ser tratada como sede do excedente populacional rural e pelo menos um terço das localidades constituiriam expressão de um novo fenômeno para a época: a segregação urbana. 


\section{Introducción}

Este artículo tiene por objetivo presentar una caracterización de la estructura urbana de las localidades ${ }^{1}$ de Uruguay, clasificando la heterogénea configuración institucional e infraestructural, premisas en la distribución local de bienestar. La pregunta más general a responder es ¿qué diferencias estructurales demográficas, sociales y económicas existían entre las localidades a comienzos de la década de 1960? La motivación de este análisis se encuentra en la prolongada discusión que hubo en el país desde 1900 sobre la emergencia de un tipo de localidad absolutamente distinta a las demás que contaba con una estructura institucional, urbanística y sociodemográfica excepcional.

Los dirigentes de las agremiaciones rurales y también los intelectuales, entre 1900 y 1960, le denominaron "rancheríos" o más despectivamente "pueblos de ratas". Esta emergencia aquí es denominada microurbanización en razón a que se trata de localidades menores a 1500 habitantes.

El enfoque más general entiende la localidad como un nodo en la distribución de bienes y servicios satisfactores de necesidades humanas (Fernández, 2001; Fernández, 2002; Fernández \& Ríos, 2013; Fernández, 2018). Nos inspiramos y retomamos así el trabajo pionero sobre la "Situación económico-social del Uruguay rural" hecho por el Centro Latino Americano de Economía Humana (CLAEH-CINAM, 1963).
El año 1960 marca el ocaso de visión del Estado y de la sociedad encarnada por el Batllismo (Marcheschi et al., 2015). En 1909, Batlle y Ordóñez asumió la presidencia, dando comienzo al primer impulso reformista socialdemócrata $(\mathrm{Pa}-$ nizza, 1990), siendo un proyecto político y social que tuvo el objetivo de constituir un "pequeño país modelo", dirigido desde el Estado (Bértola \& Bittencourt, 2015) y sustentado por una alianza con las clases intermedias urbanas. Este proyecto concluye en 1958 cuando triunfa el Partido Nacional apoyado en una alianza con los hacendados, los comerciantes y otras clases intermedias pero radicadas por fuera de Montevideo. En marzo de 1959 comenzaron los cambios estructurales con el fin de desmantelar el control del Estado en la esfera económica, principalmente (Alonso \& Demasi, 1986).

En relación con lo que aquí interesa, el cambio de partido de gobierno estuvo asociado a la incorporación sistemática de la investigación social, aplicada a la elaboración de políticas, y a la introducción de conceptos de "planificación indicativa", movimientos ambos propiciados por la CEPAL. En este sentido, en 1960 fue creada la Comisión de Desarrollo e Inversiones del Estado (CIDE). A impulso de la CIDE, se llevó adelante el ya mencionado estudio de CLAEH-CINAM, el Censo de 1963, entre otros, configurando un período inédito de estudios empíricos, diagnósticos y planificaciones, que marcó blica, Uruguay. Correo electrónico: tania.biramontes@cienciassociales. edu.uy. ORCID: https:// orcid.org/0000-00019676-3552

${ }^{1}$ Por razones que quedarán nitidas más abajo, el término "localidad" incluye todos los centros poblados, pero por lo general, excluye el tratamiento de la ciudad capital de la República, Montevideo. 
${ }^{2}$ Subdivisión del departamento que incluye territorio amanzanado o no.

\section{territarias 46}

profundamente el pensamiento sobre políticas públicas (Galván et al., 2012).

El artículo comienza revisando el problema de las microurbanizaciones y el análisis que realizado. Revisamos tres grandes enfoques formulados entre 1900 y 1960, cada uno de los cuales estuvo conectado con propuestas divergentes de política pública, desde aquellas represivas (morales o penales) contra los "malvivientes" de esos "rancheríos" hasta llegar a fundamentar programas de reforma agraria. Estas serán analizadas utilizando los microdatos del Censo de Población de 1963 mediante la técnica de análisis de clúster aplicado a las localidades.

\section{El problema}

El III Censo de Población de Uruguay fue levantado en 1908, reportando la residencia de 1042686 habitantes (López Lomba, 1909). La tabla 1 muestra la distribución, en frecuencias absolutas y relativas, de la población entre capital nacional, capitales departamentales, localidades no capitales y un estimativo de la población rural. Se puede apreciar que fuera de las capitales (nacional y departamentales), un $54 \%$ residía en zonas rurales y un $8 \%$ (equivalente a 87 mil personas) en localidades no capitales.

En la publicación oficial del Censo de 1908 no se reportaron cifras por localidades sino por secciones judiciales. ${ }^{2}$ En los años ochenta, historiadores y demógrafos reconstruyeron esta información (Rial, 1980; Klaczko, 1981), reportando haber identificado por diversas fuentes un total de 348 localidades; sin embargo, solo para 112 pudo ser reconstruida la cantidad de habitantes. De las 236 localidades restantes, 145 eran conocidas solo por su nombre o ubicación (varias de ellas eran estaciones o paradas del ferrocarril) sin otra referencia relativa a las dimensiones, fecha de fundación o tamaño.

Tabla 1. Distribución de la población según el tipo de localidad

\begin{tabular}{|l|c|c|c|c|}
\hline & \multicolumn{2}{|c|}{1908} & \multicolumn{2}{c|}{1963} \\
\hline Montevideo & 247858 & $24 \%$ (1 loc.) & 1198213 & $46 \%$ (1 loc.) \\
\hline Capitales departamentales & 145141 & $14 \%(18$ loc.) & 495295 & $19 \%$ (18 loc.) \\
\hline $\begin{array}{l}\text { Caseríos, poblados, villas, } \\
\text { pueblos y ciudades }\end{array}$ & 87519 & $8 \%(329$ loc.) & 534965 & $21 \%$ (1085 loc.) \\
\hline Rural & 562168 & $54 \%$ & 367037 & $14 \%$ \\
\hline Total población & $1,042,686$ & $100 \%(348$ loc.) & $2,595,510$ & $100 \%(1115$ loc.) \\
\hline
\end{tabular}

Nota: la información entre paréntesis corresponde a la cantidad de localidades del censo. Fuente: elaboración propia con base en los III y IV Censos de Población de Uruguay, levantados por el Ministerio de Hacienda (1908; 1963). 
El IV Censo de Población fue llevado a cabo en 1963 reportó que en Uruguay vivían 2595510 personas distribuidas en un total de 1115 localidades definidas como tales por el propio Censo. La población rural se redujo al $14 \%$, de hecho, el crecimiento censal interanual de 1,7\% se concentró en particular en Montevideo y en las 19 capitales (con tasas superiores al $2 \%$ anual, ver tabla 1 ).

Entre 1908 y 1963 se habrían establecido nuevas localidades, todas ellas incluidas en la categoría de no capitales. Solo 51 fueron establecidas oficialmente por vía de la aplicación del vigente del Decreto de Latorre de 1877 o de la Ley de 1946 (Álvarez Lenzi, 1986).

En síntesis, como se observa en la tabla 2 , en la primera mitad del siglo $\mathrm{xx}$,
Uruguay habría experimentado un doble proceso de transformación territorial, que además de registrar un incremento del peso de Montevideo, implicó un marcado proceso de microurbanización, tal como lo hemos denominado en otros trabajos (Fernández, 2018; Fernández \& Wilkins, 2019). En adelante nos concentraremos en conceptuar y explicar este proceso multiplicador de poblados menores a 1500 habitantes.

\section{Marco teórico}

La explosión microurbana fue abordada en reiteradas ocasiones y por distintos actores (gremiales, políticos, eclesiales, académicos) entre 1900 y 1963. Lo más destacable es que la explicación fue

Tabla 2. Número de localidades según región y departamento. Uruguay, 1963

\begin{tabular}{|l|c|c|c|c|c|}
\hline & $\begin{array}{c}\text { Caseríos } \\
\text { (hasta 300 hab.) }\end{array}$ & $\begin{array}{c}\text { Poblados } \\
(\mathbf{3 0 0} \text { a 1499 hab.) }\end{array}$ & $\begin{array}{c}\text { Pueblos \& Villas } \\
\text { (desde 1500 hab.) }\end{array}$ & Ciudades & Total \\
\hline Montevideo & 0 & 1 & 2 & 1 & 4 \\
\hline Gran Canelones & 108 & 31 & 17 & 9 & 165 \\
\hline Suroeste & 104 & 20 & 6 & 8 & 138 \\
\hline Litoral & 141 & 37 & 10 & 8 & 196 \\
\hline Noreste & 209 & 27 & 3 & 4 & 244 \\
\hline Merin & 60 & 10 & 5 & 4 & 75 \\
\hline Este & 71 & 9 & 4 & 5 & 204 \\
\hline Central & 172 & 23 & 51 & 41 & 1,115 \\
\hline Total & 865 & 158 & & 2 & 89 \\
\hline
\end{tabular}

Fuente: elaboración propia con base en microdatos del Censo de 1963. 
ensayada (con una sola excepción) sin información empírica de origen censal, pero con gran potencial teórico.

\section{El tratamiento del tema entre 1900 y 1960}

El incremento de localidades urbanas por la vía del incremento de caseríos y poblados en los departamentos del interior fue tema central de los Congresos de la Asociación Rural del Uruguay (ARU). Preocupaba el problema del pauperismo y de la seguridad rural, con el foco puesto en el agrupamiento de familias pobres asentadas en predios públicos (Chiarino \& Saralegui, 1944). El $9^{\circ}$ Congreso Rural de 1909 crea una Comisión de estudios para "mejorar la situación de la gente pobre de la campaña" (García Acevedo, 1967). Esta Comisión, que trabajó durante 1910, realizó lo que probablemente haya sido la primera encuesta a gran escala en el país. El informe presentado al $10^{\circ}$ Congreso de 1910 sobre la base del procesamiento de estas encuestas, hizo tres aportes perdurables al debate: (i) un estudio sobre las causas de la pobreza; (ii) una recomendación de 10 medidas de política pública para su superación; y (iii) la reconceptualización del problema del pauperismo, en términos de segregación y exclusión residencial, dando origen al término "pueblos de ratas". El informe de García Acevedo también aportó una georreferenciación de estos poblados: resalta su importancia en los departamentos de Salto, Artigas, Rivera, Tacuarembó y Cerro Largo, que por esa época conformaban una clara región norte de matriz productiva bicéfala ganadera y comercial.

Luego de la Primera Guerra Mundial, otra fue la posición mayoritaria en los congresos rurales de 1919 a 1936, el pauperismo con causa económica fue desplazado por el problema de los "vicios morales" de los pobres rurales (vagancia, alcoholismo, juego, prostitución, robo). En forma solo minoritaria, subsistió otra línea que podríamos tildar extemporáneamente de demócrata-cristiana que mantuvo el acento en las condiciones estructurales que presentaban estas estas áreas microurbanas, donde no había acceso, ni por el Estado ni por el mercado, a la satisfacción de las necesidades humanas (Martínez Lamas, 1930; Brena, 1936). Posteriormente, fue publicado el libro Detrás de la ciudad, de Chiarino y Saralagui (1944), que recopiló todos los estudios realizados sobre el tema.

Esos pueblos en formación tiene su razón de ser; pero una parte de estos pueblos, que forman el sector de rancheríos de los mismos, o los que están constituidos por puro rancherío, y situados en el medio del campo, no tienen en realidad ninguna razón de ser, económica o de labor [...] El rancherío típico, el rancherío puro y total, es ese que se forma en el medio del campo, generalmente de puros ranchos de terrón, con techos unas veces de paja, otras las menos de hierro galvanizado, otras de 
latas, los antiguos recipientes de kerosene [...] El rancherío empieza a nacer espontáneamente, ubicándose donde puede [...] Algunos, tal vez más de los que se piensa, se han constituido por descendientes de una misma familia. [...] En otros casos, los terrenos han sido fiscales, pero nos inclinamos a creer que por lo general el origen posesivo haya derivado de la indefinición legal de la propiedad particular [...] No faltan tampoco, sobre todo entre los rancheríos de más reciente data, los formados por expresa división hecha por los propietarios de pequeñas propiedades, desgraciadamente sin ningún contralor de la autoridad municipal. De los más de 600 [...] solamente 89, muchos de ellos muy pequeños, son los que no tienen escuela. (Chiarino \& Saralegui, 1944, pp. 159-162)

En esa misma década, otras dos vertientes de tratamiento del problema aparecen en el debate político y académico. Por un lado, cobra vigor el análisis marxista sobre el tema de los campos con base en los escritos de Lenin. Por otro lado, el análisis crítico que impulsan los maestros, con base en la experiencia de las Misiones Pedagógicas, desarrollado en 1949 que contaba con un enfoque de promoción humana y desarrollo social del área local donde está inserta la escuela (García Alonso \& Scagliola, 2012).

En la década de los cincuenta, el tema ingresa con uno de los principales autores de la novel sociología nacional: Aldo Solari (1954) y Carlos Rama presenta $D e$ la singularidad de la urbanización en el Uruguay (Rama, 1959). Para 1963 el CLAEH-CINAM presenta su monumental informe sobre la Situación económica y social del Uruguay rural (1963).

Ahora bien, ¿qué explicaciones han sido propuestas para esta microurbanización? Expondremos a continuación tres grandes hipótesis que luego contrastamos empíricamente.

\section{Hipótesis sobre la expansión informal de la urbanización}

Una primera hipótesis que encuentra apoyo en la bibliografía, básicamente proveniente de estudios urbanísticos, permite sostener que la expansión indicada en la tabla 3, tendría que ver con la debilidad que caracterizó al marco regulatorio vigente, por lo menos hasta 1946, en relación con el establecimiento de nuevas localidades. Hasta esa fecha hubo dos regímenes legales sucesivos: las Leyes de Indias (Icaza Dufour, 1987) y el "Reglamento para la fundación de pueblos y colonias" de 1877 (Álvarez Lenzi, 1986). La Ley de Centros Poblados (1946), actualmente vigente, representó un cambio importante en la medida que deslindó definitivamente las responsabilidades entre el nivel de gobierno departamental y el nivel de gobierno nacional, atribuyéndole al primero la fiscalización del cumplimiento de las distintas exigencias urbanísticas y legales del establecimiento. Previo a esto, el cumplimiento de estas obligaciones y 
su fiscalización estaban centralizadas en Montevideo, lo que agregaba otro desincentivo adicional (la distancia) para su cumplimento.

Tabla 3. Distribución de las localidades según el período de fundación y el tamaño

\begin{tabular}{|l|c|c|}
\hline \multicolumn{1}{|c|}{ Período histórico } & $\begin{array}{c}\text { N. } .^{\mathbf{0}} \\
\text { localidades }\end{array}$ & $\%$ \\
\hline $\begin{array}{l}\text { Período de la Colonia } \\
\text { Española (hasta 1810) }\end{array}$ & 23 & $2 \%$ \\
\hline $\begin{array}{l}\text { Guerras de Independencia } \\
\text { (1811-1829) }\end{array}$ & 3 & $0 \%$ \\
\hline Guerras Civiles (1830-1874) & 32 & $3 \%$ \\
\hline $\begin{array}{l}\text { El Militarismo y la República } \\
\text { Oligárquica (1875-1908) }\end{array}$ & 223 & $20 \%$ \\
\hline $\begin{array}{l}\text { El Primer Batllismo (1909- } \\
\text { 1933), Terra (1933-1938) y } \\
\text { Neobatllismo (1943-1958) }\end{array}$ & 834 & $75 \%$ \\
\hline Total & 1115 & $100 \%$ \\
\hline
\end{tabular}

Fuente: elaboración propia con base en microdatos del Censo de 1963, INE (2008) y Klaczko (1981).

Una teoría de la informalidad comparte con otras teorías de este tipo (que aplican al mercado de trabajo) una caracterización de la ineficacia del Estado en regular relaciones sociales, en especial aquellas en las que la iniciativa privada se adelanta a la provisión de necesidades (en este caso, de urbanización). En consecuencia, si bien han de observarse que estas ciudades nacieron informales, este evento no debería asociarse a que transcurrido el tiempo, no fueran formalizadas, ni que tuvieran necesariamente otros rasgos, por ejemplo, de precariedad infraestructural como es mostrado en las fotografías contemporáneas (figura 1).

\section{Hipótesis sobre el excedente de población rural}

Esta segunda hipótesis tuvo su origen en el informe de García Acevedo, que estableció entre las nueve causas de la pobreza rural la desocupación forzosa por la valorización de la tierra y la falta de trabajo, especialmente en aquellos departamentos donde la ganadería es la única explotación (García Acevedo, 1967). Esta hipótesis fue usada por Chiarino y Saralegui (1944, p. 159) en su capítulo sobre los rancheríos que les sirve para distinguir a estos de los “pueblos de formación” conurbados. Esta hipótesis fue retomada y refinada teóricamente por la naciente sociología nacional de los cincuenta (Solari, 1954; Rama, 1959; Rama, 1960; Martorelli, 1969; Wettstein \& Rudolf, 1969).

Estas localidades serían el resultado del proceso de modernización tecnológica de las estancias entre fines del siglo XIX y el comienzo del siglo XX. La introducción del alambrado, las subdivisiones dentro del predio, el marcado del ganado, los cambios en el manejo, el mejoramiento de la policía rural, la reducción del abigeato y la extensión de la práctica de contratar jornaleros durante el período de esquila, conllevaron a que los estancieros despidieran trabajadores y familias enteras que solían vivir como allegados 
Figura 1. Fotografías de los años cuarenta de ranchos en la localidad de Tianticura, Paysandú
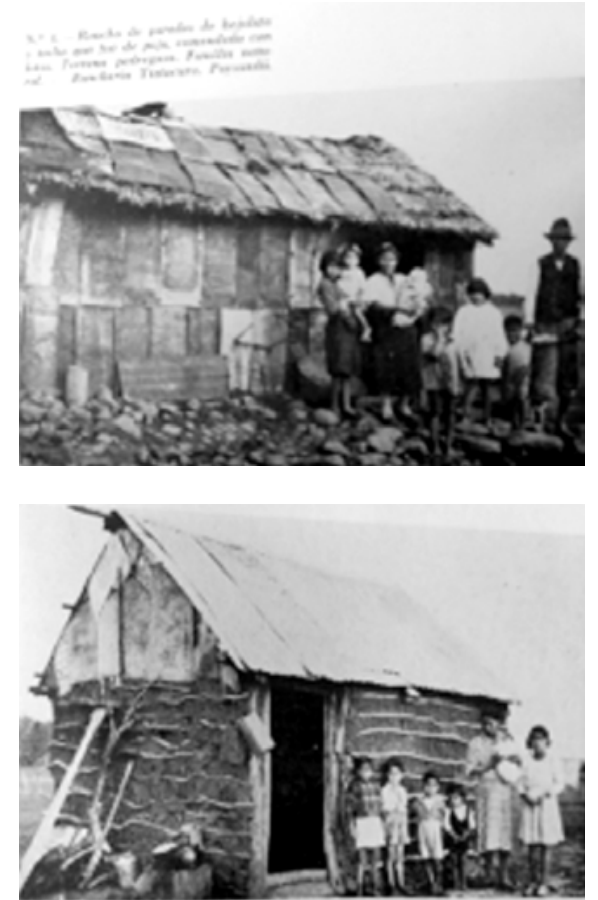

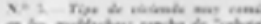
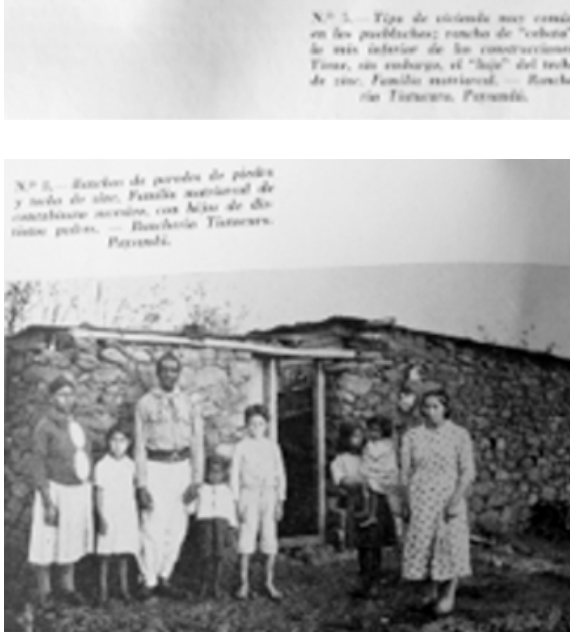

Fuente: tomado de Chiarino y Saralegui (1944). de la estancia. Los expulsados se fueron localizando junto a los caminos, cerca de almacenes de campaña, en las orillas de los arroyos o próximo a las estaciones del ferrocarril. A la externalización del costo de la reproducción biológica y social de este proletariado rural, se agregaría su carácter disponible como reserva para satisfacer incrementos estacionales en la demanda de fuerza de trabajo.

Conforme a esta hipótesis, las localidades debieran mostrar indicadores de empleo pautados por la precariedad: jornaleros y peones, desempleados, con baja proporción de empleados de forma permanente en el sector rural y por supuesto, también en la industria y en los servicios. Además, tal como lo indicaba García Acevedo (1967), debían predominar en el norte, noreste y centro del país donde prevalece el modelo de estancia ganadera.

\section{Hipótesis sobre la segregación residencial}

Sostiene que el origen de las microlocalidades es la segregación hacia la periferia rural de las ciudades. Terra (1969) propone que algunos instrumentos legales, incentivaron un marcado incremento en la inversión inmobiliaria en áreas residenciales de Montevideo y en algunas de las ciudades grandes del interior, modificando especulativamente el precio del suelo, desplazando inquilinos, generando aumento de alquileres en otras zonas ya urbanizadas. Este incremento a su vez, tersitarios 46 
asociado a la baja inversión en vivienda popular, conllevó a que las categorías sociales con menor capital y empleos precarios se vieran progresivamente forzados a afincarse en loteos, algunos irregulares, hechos en las otrora zonas de chacras definidas por las normas de creación urbana (Icaza Dufour, 1987; DGO, 1877; Álvarez Lenzi, 1986) y en tierras fiscales no ocupadas (por ejemplo, márgenes de cursos de agua, zonas inundables, etc.) (Terra, 1969, pp. 33-35). El resultado fue la segregación espacial y la precariedad habitacional: casas con marcadas ineficiencias para satisfacer las necesidades humanas de resguardo, acondicionamiento térmico e intimidad (Fernández, 2010; Martorelli, 1969).

Este proceso se mapeó con detalle en torno a las principales rutas que llegaban a Montevideo y en los alrededores de otras capitales departamentales. El fenómeno también se observaba en las villas de tamaño medio: por ejemplo, junto a Tranqueras, Tranqueras Chico.

Si esta hipótesis fuera correcta, la distribución en el territorio de estas localidades debería observarse concentrada en torno a las ciudades capitales, más precisamente en las secciones judiciales en las que está comprendida la capital. En segundo lugar, debería observarse una alta prevalencia de tenedores de la vivienda a título precario o sin título. Finalmente, debieran observarse niveles importantes de infraestructura habitacional marcadamente deficitaria: predominio de casas con techos ligeros sin cielorraso, paredes de desecho y pisos de tierra o escombro.

\section{Hipótesis de este trabajo}

Si bien, originadas en contextos históricos y teóricos diferentes, las tres hipótesis presentadas no son necesariamente contrapuestas ni excluyentes, sino posiblemente cada una puede dar cuenta de una parte en la heterogeneidad de la estructura territorial del país en la primera mitad del siglo Xx. Al menos en forma descriptiva, tales clasificaciones de localidades podrían yuxtaponerse al punto de identificar, por ejemplo, un núcleo duro de localidades pobres, informales, conformadas por población excedentaria pobreza rural, en tanto que, otro núcleo sería de localidades urbanas informales, pero no necesariamente vinculadas con el éxodo rural ni originarias en la tercera hipótesis de la segregación urbana. No todas las pequeñas localidades eran de un mismo tipo ni obedecerían a un mismo proceso histórico-territorial. Estas clasificaciones derivadas de las tres hipótesis, si bien con algunas yuxtaposiciones, tenderían a distribuirse entre las regiones del país, agregando un nuevo factor de diferenciación territorial (CLAEH-CINAM , 1963; Fernández, 2018; Fernández \& Wilkins, 2019). Analizaremos esta hipótesis luego de analizar las tres primeras. 


\section{Datos y métodos}

La unidad de análisis en este artículo es la localidad. Sin perjuicio de esto, el análisis incluye una distinción de otros niveles considerados, como: el Estado-nación; el departamento y las regiones socioeconómicas, delimitadas básicamente por su matriz agroproductiva, tal como fuera descripta por CLAEH-CINAM (1963).

\section{Fuentes de información}

Las fuentes principales de información para este período son tres: (i) los Censos de población de 1908 y de 1963; (ii) el trabajo de la demografía histórica sobre el Uruguay del 900, en particular el listado de centros poblados elaborado por Klaczko (1981); y (iii) los índices toponímicos publicados por la Dirección General de Estadísticas y Censos en 1971 y 1989 (Davrieux, 1972; DGEyC, 1989).

Los distintos problemas de comparación entre los Censos 1908 y 1963 incluyen: que el primero no reportó por localidad sino por sección judicial, en tanto que la documentación del segundo carece del diccionario de localidades, entre otros codificadores. ${ }^{3}$ El ya mencionado trabajo de demografía histórica de Klaczko (1981) subsana el primer problema. El segundo ha sido objeto de un extenso trabajo (Fernández \& Wilkins, 2019).

\section{Identificación de las localidades}

Hasta el presente, cuatro han sido las publicaciones oficiales hechas por la dependencia oficial encargada de los Censos. La primera contiene los datos agregados producto del "Índice toponímico de centros poblados", publicado casi una década después del Censo de 1963 (Davrieux, 1972). Este incluyó localidades codificadas por el Censo y con información publicada en los boletines departamentales, así como información de otras tres mil ochocientas localidades, de las cuales no hay información censal. La segunda (1989) y la tercera publicación (1999) son consecuencia directa de los Censos de 1985 y de 1996. La publicación del Instituto Nacional de Estadísticas contiene información histórica de la población de la localidad, pero solo incluyó aquellas 170 creadas o reconocidas por vía de Ley o Decreto (INE, 2008).

Ahora bien, no existen antecedentes que conozcamos que hayan conformado un listado de localidades que incluya a los Censos de 1908, 1963 y 1975, a los efectos de vincularlas con los más recientes toponímicos. Un documento del INE cuenta con un listado extenso en el que se pueden encontrar localidades que dejaron de estar vigentes para el Censo de 1985, 1996 y 2011 (INE, 2018). Pero no hay un listado inverso: esto es, localidades identificadas en 1963 o antes, que dejaran
${ }^{3}$ La versión en uso del Censo de 1963 fue recuperada por el Centro Latinoamericano de Demografía, CELADE, ya que los originales se extraviaron. Existe documentación impresa sobre el Censo de 1963 que está incompleta y que no siempre es consistente con lo registrado. 
de ser registradas para 1985 y posteriores relevamientos.

Esta dispersión, ausencia y contradicciones conllevó un trabajo previo de los autores (Fernández \& Wilkins, 2019). La información de los trabajos de Klaczko (1981), de Rial (1980) y del Toponímico de 1971 fue digitada, conformándose bases de datos. Conjuntamente con la información censal agregada por localidades de 1963, el toponímico de 2018 y con los boletines departamentales, se procedió a triangular información, determinando el código y nombre de la localidad conforme a los codificadores del INE. También se relevaron una veintena de trabajos históricos de diversa naturaleza publicados sobre localidades del país. La tabla 4 resume el número de localidades identificadas y las no identificadas para cada relevamiento censal.

Tabla 4. Número de localidades identificadas en los Censos de 1908, 1963 y 1985

\begin{tabular}{|l|c|c|c|}
\hline \multicolumn{1}{|c|}{ Localidades } & 1908 & 1963 & 1985 \\
\hline Identificada & 149 & 1076 & 636 \\
\hline Sin información disponible & 163 & 0 & 0 \\
\hline $\begin{array}{l}\text { No identificada } \\
\text { geográficamente }\left(^{*}\right)\end{array}$ & 14 & 39 & 0 \\
\hline Total & 326 & 1115 & 636 \\
\hline
\end{tabular}

Nota: la información en (*) se refiere a localidades que, si bien están codificadas en bases o listados, no se puede identificar su localización en la cartografía disponible y no hay mayores datos. Fuente: elaboración propia con base en microdatos de los Censos 1963 y 1985, y Klaczko, 1981.

\section{Tamaño de la población}

Dado que esta es una variable importante en el concepto de microurbanización, lo hemos definido operacionalmente; primero, con base en las categorías de localidades establecidas en el propio Censo; y luego, con base en el número de habitantes registrados.

Ahora bien, el Censo aplicó tres criterios diferentes. Primero, el criterio legal, nombrando la localidad según fuera oficialmente villa, pueblo o ciudad. Pero solo hubo 143 localidades oficializadas en ese momento. En segundo lugar, aplicó para las no clasificadas con el primer criterio, otro demográfico: estableció denominar centro poblado a las localidades que tuvieran mayor densidad de servicios y que pudieran considerarse un pueblo incipiente o en formación. Cuando este no fuera el caso, pero que hubiera al menos 10 viviendas separadas como máximo 100 metros entre sí, y que, sus habitantes se identifican pertenecer al mismo, entonces la localidad fue denominada caserío. Las restantes localidades clasificaron como viviendas aisladas. Finalmente, el Censo aplicó un tercer criterio, a través del cual renombró algunas localidades conforme a "un hecho, realidad geográfica o productiva”. De aquí surgieron las categorizaciones de balneario, puerto, barrio rural, isla, campamento, entre otros (DGEyC, 1965, pp. 17-18).

Para este estudio, resolvimos dar prioridad al criterio demográfico, en el que 
Figura 2. Regionalización del Uruguay

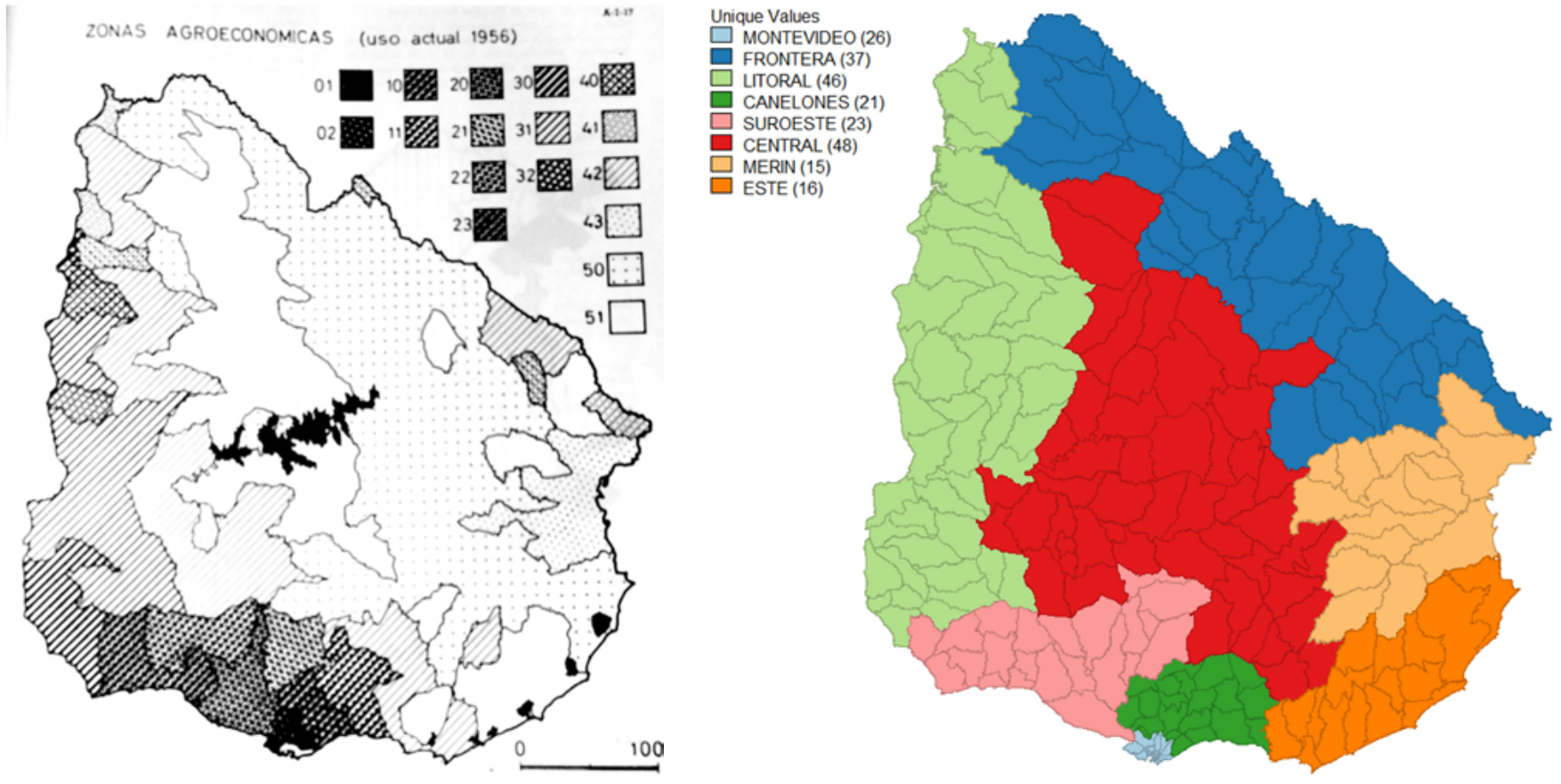

Nota: a la izquierda, el mapa lA muestra las zonas agroeconómicas identificadas por el estudio del CLAEH-CINAM (1963); a la derecha, en el mapa IB se ve la regionalización sociohistórica. Fuente: CLAEH-CINAM (1963) y Fernández (2018).

distinguimos tres grandes categorías. Las viviendas aisladas, caseríos y poblamientos son aquellas localidades que cuentan hasta 299 habitantes. Como poblados clasifican aquellas que tienen al menos 300 habitantes y menos de 1499. En contraposición, con base en este criterio demográfico, todas las demás localidades con 1500 y más habitantes clasifican como Pueblos, Villas y Ciudades. Esta recodificación permitió discutir la naturaleza de las microurbanizaciones y, en particular, la relación de estas con la acción estatal de oficialización.

\section{Regiones socioeconómicas}

El estudio de CLAEH-CINAM (1963) construyó una clasificación con 17 zonas agroeconómicas, que representaba la diversidad de suelos, rubros y matrices productivas del país (mapa $1 \mathrm{~A}$ de la figura 2). Las zonas 1 y 2 , hortofrutícolas, con las zonas 10 y 11 , que agregan la vitivinicultura, se desarrollaron en el área sur del país caracterizada por la pequeña propiedad y la agricultura. Las zonas 20 a 23 , son áreas de transición que combinan esos rubros con la lechería en medianas territarias 46 
propiedades y con fuerte presencia de inmigrantes y de colonias agrícolas instaladas en el suroeste del país (Colonia, Soriano y San José al sur).

Las zonas 30 a la 41 combinaron producción cerealera, citrícola, oleaginosa y ganadera en medianos y grandes establecimientos rurales. La zona 42 comprende amplios territorios de transición, con establecimientos grandes, donde incorporaron el lanar además del vacuno, también desde fines del siglo XIX. Las restantes tres zonas, representan casi la mitad de las tierras productivas del país, donde predominaba la ganadería extensiva vacuna y bovina, en diferentes tipos de propiedades, pero siempre con baja incorporación de mano de obra y tecnología.

Estas zonas agroeconómicas no tienen base exclusivamente geológica, sino que son territorios históricamente construidos durante más de trescientos años en los que se articularon procesos políticos, migratorios, tecnológicos, vías de comunicación, para consolidar regiones bastante definidas (Fernández, 2018). Aplicada al Censo de 1963, esta es la regionalización que se utilizará en el presente estudio, tal como se muestra en el mapa $1 \mathrm{~B}$ de la figura 2.

\section{Indicadores de las hipótesis alternativas}

Se construyeron variables para el nivel de localidad en distintas fuentes disponibles.

\section{territarias 46} En varios casos, solo fue posible aproximarse a la dimensión original, sobre todo porque el Censo de 1963 carece de esta información, o habiéndola recogido, su codificación no está documentada. Como síntesis de la operacionalización se muestra la tabla 5 , en la que se señalan las variables utilizadas para reflejar cada una de las hipótesis.

El problema de información principal está en la migración: no está documentada la localidad de nacimiento; solo el departamento de nacimiento y el departamento de residencia previo a la migración, en los casos que correspondiera.

Las variables de actividad y empleo están registradas en forma sencilla y para toda persona con ocho y más años de edad. La tasa de actividad es calculada con base en toda la población con ocho y más años de edad. Sin embargo, la desocupación se mide solo para varones con 15 y más años de edad. La restricción de género se aplica para evitar esconder alto desempleo por una mayor actividad femenina. La condición de ocupado se registra al día del Censo, realizado a mediados de octubre, sobre la finalización de la esquila, por tanto, una época de alta demanda de trabajo del sector agropecuario. Esto podría haber llevado a una sobreestimación de la actividad y de ocupación en el sector agropecuario, así como una subestimación de la tasa de desocupación. Ambos aspectos representan serias amenazas a las inferencias que se puedan hacer al analizar la hipótesis 2 .

La noción de conurbado fue aplicada en forma aproximada con base en la 
Tabla 5. Dimensiones, variables y fuentes para las hipótesis

\begin{tabular}{|c|c|c|c|}
\hline Hipótesis & Variable original & Fuente & Indicador localidad \\
\hline \multirow{3}{*}{ Informalidad } & Período de fundación & Toponímico 2008 & $\begin{array}{l}\text { La localidad fue fundada } \\
\text { luego de } 1908\end{array}$ \\
\hline & $\begin{array}{l}\text { Status legal que tiene } \\
\text { la localidad a } 1963\end{array}$ & $\begin{array}{l}\text { Digesto de Leyes y Decretos; } \\
\text { índice toponímico de } \\
2008 \text { (INE, 2008) }\end{array}$ & $\begin{array}{l}\text { La localidad no tiene status } \\
\text { formal; es un pueblo; es } \\
\text { una villa; es una ciudad }\end{array}$ \\
\hline & $\begin{array}{l}\text { Vivienda en predio } \\
\text { amanzanado }\end{array}$ & $\begin{array}{l}\text { IV Censo de Población } \\
\text { (1963), cuestionario hogares }\end{array}$ & $\begin{array}{l}\text { Más del } 20 \% \text { de las } \\
\text { viviendas se encuentran en } \\
\text { predios amanzanados }\end{array}$ \\
\hline \multirow{4}{*}{$\begin{array}{l}\text { Excedente de } \\
\text { fuerza de trabajo }\end{array}$} & \multirow{4}{*}{$\begin{array}{l}\text { Población } \\
\text { excedentaria rural }\end{array}$} & $\begin{array}{l}\text { IV Censo de Población } \\
(1963), \text { cuestionario } \\
\text { personas }\end{array}$ & $\begin{array}{l}\text { \% Desocupación } \\
\text { abierta masculina }\end{array}$ \\
\hline & & $\begin{array}{l}\text { IV Censo de Población } \\
(1963) \text {, cuestionario } \\
\text { personas }\end{array}$ & $\begin{array}{l}\% \text { Desocupación abierta } \\
\text { varones jóvenes (15 a } 29 \text { años) }\end{array}$ \\
\hline & & $\begin{array}{l}\text { IV Censo de Población } \\
(1963), \text { cuestionario } \\
\text { personas }\end{array}$ & $\begin{array}{l}\% \text { personas activas trabajando } \\
\text { en el sector agropecuario }\end{array}$ \\
\hline & & $\begin{array}{l}\text { IV Censo de Población } \\
(1963), \text { cuestionario } \\
\text { personas }\end{array}$ & $\begin{array}{l}\text { \% Fuerza de trabajo no } \\
\text { calificada de tipo ocasional }\end{array}$ \\
\hline \multirow{5}{*}{$\begin{array}{l}\text { Segmentación } \\
\text { residencial }\end{array}$} & $\begin{array}{l}\text { Formalización } \\
\text { de la propiedad } \\
\text { habitacional }\end{array}$ & $\begin{array}{l}\text { IV Censo de } \\
\text { Población (1963) } \\
\text { Cuestionario de viviendas }\end{array}$ & $\begin{array}{l}\text { \% viviendas con título } \\
\text { precario de tenencia (ocupante } \\
\text { de hecho, evacuado, otros) }\end{array}$ \\
\hline & \multirow{3}{*}{$\begin{array}{l}\text { Infraestructura } \\
\text { habitacional }\end{array}$} & $\begin{array}{l}\text { IV Censo de Población } \\
\text { (1963), cuestionario hogares }\end{array}$ & $\begin{array}{l}\text { \% viviendas con techos } \\
\text { de chapa ( } \text { in cielo raso, } \\
\text { paja, desechos, etc.) }\end{array}$ \\
\hline & & $\begin{array}{l}\text { IV Censo de Población } \\
\text { (1963), cuestionario hogares }\end{array}$ & $\begin{array}{l}\% \text { viviendas con paredes de } \\
\text { desecho (madera, zinc, barro, } \\
\text { lata, material de desecho) }\end{array}$ \\
\hline & & $\begin{array}{l}\text { IV Censo de Población } \\
(1963), \text { cuestionario hogares }\end{array}$ & $\begin{array}{l}\text { \% viviendas con piso de tierra, } \\
\text { ladrillo molido, piedras, } \\
\text { cascotes, escombros }\end{array}$ \\
\hline & Metropolitanciación & Cartografía censal 1963 & $\begin{array}{l}\text { Localidad conurbada } \\
\text { a la capital }\end{array}$ \\
\hline
\end{tabular}

Fuente: elaboración propia. 
cartografía censal. Se operacionalizó la sección censal número 1 , donde se ubica la capital departamental, y se agregaron de otras secciones censales aquellos segmentos siempre que estos fueran linderos con la sección l. Este fue el procedimiento aplicado para identificar las conurbanizaciones en Salto, Tacuarembó, Rivera y Paysandú. En otros casos, como en Colonia del Sacramento, Minas, Fray Bentos y Mercedes, la sección 1 tiene dimensiones que exceden esta noción, aunque a efectos de este trabajo no hicimos recortes. Un total de 100 localidades fueron clasificadas como conurbadas conforme a este método, siendo el $75 \%$ menores a 300 habitantes.

\section{Método de clasificación}

Aplicamos un modelo taxonométrico mediante cluster analysis (análisis de conglomerado), de tipo jerárquico aglomerativo (Everitt, Landau, Leese, \& Stahl, 2011). Dado que utilizaremos variables tanto métricas como dicotómicas utilizamos el estadístico de Gower y como método de agrupamiento el de Ward. En el caso de variables dicotómicas, utilizamos el estadístico de Dice-Sorensen. Este tiene la peculiaridad de descartar del cómputo la ausencia del atributo (código 0 ) en las dos variables. El método Ward de aglomeración minimiza la disimilitud intragrupal. Tiene la ventaja de imponer el requisito de menor disimilitud para fusionar elementos en un grupo, generando grupos más homogéneos. Pero tiene la desventaja de generar un mayor número de grupos que otros métodos (Everitt et al., 2011).

Utilizamos Duda-Hart (DH) y Calinski-Harabasz $(\mathrm{CH})$ como stoping-rules. Tal como informa la bibliografía (Everitt et al., 2011, pp. 126-127; Halpin, 2016, pp. 3-4), estos criterios no suelen ser consistentes, pero en el caso del criterio $\mathrm{DH}$, la combinación entre el índice $\mathrm{DH}$ y el valor del estadístico de prueba $\mathrm{T}^{2}$ genera un problema de optimización no fácilmente soluble. No existen a la fecha formas completamente satisfactorias de resolver estos problemas, por lo que la final determinación del número de grupos en la matriz termina siendo una tarea discrecional del investigador. En este caso, adoptamos los siguientes tres criterios: (a) se tomará aquella solución que converja $\mathrm{CH}$ y $\mathrm{DH}$; (b) no siendo posible, se tomará la solución que informe el mayor número de aglomerados siempre que la solución provista por uno de los criterios no duplique el número sugerido por el otro; y (c) en el caso de que una de las soluciones duplique a la otra, se tomará la menor. El objetivo es maximizar la heterogeneidad entre grupos sin generar soluciones de hiperfragmentación.

\section{Hallazgos}

Hechos varios ejercicios de clúster para el análisis de cada teoría, analizando la robustez de los hallazgos frente a cada opción de método, se presentan a 
Figura 3. Dendrograma análisis de clúster para la hipótesis 1

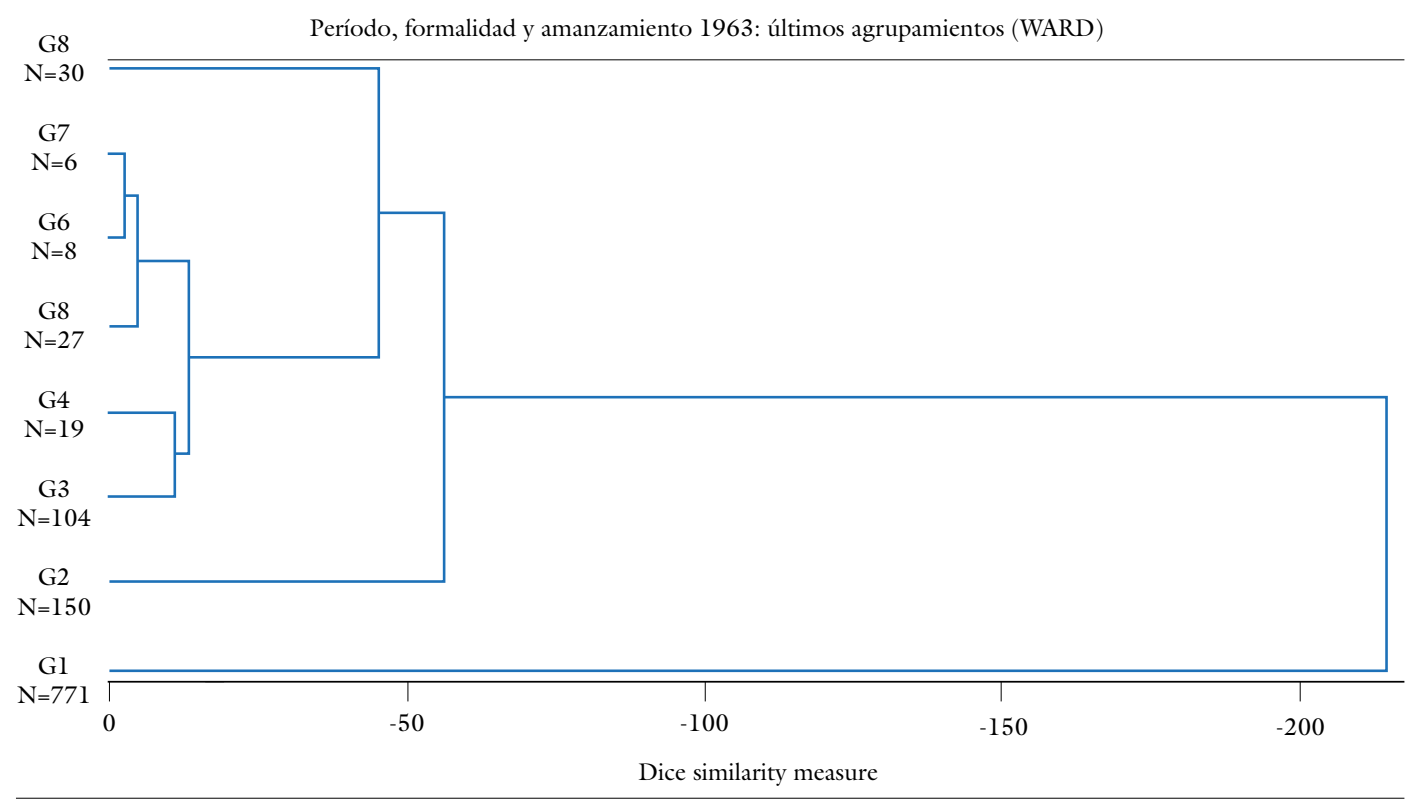

Fuente: elaboración propia con base en microdatos del Censo de Población de 1963.

continuación solo aquellas que cumplen con los criterios metodológicos adoptados.

\section{Clúster con base en la teoría de la informalidad}

Esta teoría genera matemáticamente un espacio tridimensional con ocho posibles combinaciones lógicas. El análisis de clúster resulta de utilidad en la medida en que genera una solución satisfactoria con un menor número de agrupamientos. La figura 3 muestra el dendrograma.

El estadístico DH permite retener una solución con cuatro clústeres, en tanto el criterio $\mathrm{CH}$ sugiere ocho por construcción. Conforme a la regla, seleccionamos cuatro conglomerados. La solución presenta diferencias marcadas en los valores de las tres variables para tres de los cuatro grupos, tal como se puede ver en la tabla 6 .

Tabla 6. Caracterización de los clústeres para la hipótesis de la informalidad

\begin{tabular}{|l|c|c|c|c|}
\hline & $\mathbf{1}$ & $\mathbf{2}$ & $\mathbf{3}$ & $\mathbf{4}$ \\
\hline $\begin{array}{l}\text { Número de } \\
\text { localidades }\end{array}$ & 771 & 150 & 164 & 30 \\
\hline $\begin{array}{l}\text { Establecida } \\
\text { luego de 1908 }\end{array}$ & $100 \%$ & $100 \%$ & $21 \%$ & $0 \%$ \\
\hline Amanzanada & $0 \%$ & $100 \%$ & $91 \%$ & $0 \%$ \\
\hline $\begin{array}{l}\text { Localidad } \\
\text { oficializada }\end{array}$ & $0 \%$ & $0 \%$ & $88 \%$ & $0 \%$ \\
\hline Total & $100 \%$ & $100 \%$ & $100 \%$ & $100 \%$ \\
\hline
\end{tabular}




\begin{tabular}{|l|c|c|c|c|}
\hline & $\mathbf{1}$ & $\mathbf{2}$ & $\mathbf{3}$ & $\mathbf{4}$ \\
\hline $\begin{array}{l}\text { Tamaños de } \\
\text { localidad según } \\
\text { clúster (\%) }\end{array}$ & $94 \%$ & $64 \%$ & $13 \%$ & $77 \%$ \\
\hline $\begin{array}{l}\text { Caseríos (hasta } \\
299 \text { hab.) }\end{array}$ & $6 \%$ & $32 \%$ & $36 \%$ & $23 \%$ \\
\hline $\begin{array}{l}\text { Poblados (300 } \\
\text { a 1499 hab.) }\end{array}$ & $0 \%$ & $3 \%$ & $27 \%$ & $0 \%$ \\
\hline $\begin{array}{l}\text { Pueblos \& Villas } \\
\text { Ciudades }\end{array}$ & $100 \%$ & $100 \%$ & $100 \%$ & $100 \%$ \\
\hline Total & $10 \%$ & $24 \%$ & $0 \%$ \\
\hline
\end{tabular}

Fuente: elaboración propia con base en microdatos del Censo de Población de 1963.

El grupo 1 es el más extenso y todas sus localidades son informales, no amanzadas y establecidas con posterioridad al Censo de 1908; predominan localidades menores a 300 habitantes en 1963. La dimensión del grupo 1 contrasta con una de las imágenes que había en 1960, a saber, que el número de rancheríos habría disminuido desde 1940 debido a las migraciones urbanas (Solari, 1954). El número supera estimaciones hechas con base en clasificaciones oficiales de la época y están más próximas a estimaciones que se hacían desde la academia (Wettstein \& Rudolf, 1969, p. 30).

En el grupo 2 clasifican localidades también posteriores a 1908, pero todas amanzanadas; predominan los caseríos, pero un tercio son centros poblados entre 300 y 1499 habitantes. El grupo 3 es heterogéneo en tamaño, aunque informa de localidades consolidadas, ya sea por una mayor historia o por la formalización legal. Resta el grupo 4, más reducido, que si bien tiene historia (establecido antes de 1908) no ha sido amanzanado ni formalizado; tres de cada cuatro tienen menos de 300 habitantes. En su mayoría, Klaczko (1981) los categorizó como estaciones del ferrocarril.

Desde el punto de vista regional, existen perfiles nítidos (tabla 7). Nos concentramos en el clúster 1 , predominando en todas las regiones, se destaca su mayor incidencia en el Noreste y en el Centro. En estas regiones el poblamiento fue comparativamente más tardío, no hubo fundaciones formales hasta 1837 , siendo las siguientes pocas y esparcidas en el tiempo.

Tabla 7. Distribución de los tamaños de localidad y de las regiones dentro de los clústeres para la hipótesis de la informalidad

\begin{tabular}{|l|c|c|c|c|c|}
\hline $\begin{array}{c}\text { Distribución } \\
\text { según región (\%) }\end{array}$ & $\mathbf{1}$ & $\mathbf{2}$ & $\mathbf{3}$ & $\mathbf{4}$ & Total \\
\hline Montevideo & $0 \%$ & $0 \%$ & $100 \%$ & $0 \%$ & $100 \%$ \\
\hline Canelones & $45 \%$ & $39 \%$ & $15 \%$ & $1 \%$ & $100 \%$ \\
\hline Suroeste & $62 \%$ & $15 \%$ & $20 \%$ & $4 \%$ & $100 \%$ \\
\hline Litoral & $68 \%$ & $10 \%$ & $18 \%$ & $4 \%$ & $100 \%$ \\
\hline Noreste & $84 \%$ & $4 \%$ & $9 \%$ & $3 \%$ & $100 \%$ \\
\hline Merin & $75 \%$ & $13 \%$ & $12 \%$ & $0 \%$ & $100 \%$ \\
\hline Este & $67 \%$ & $10 \%$ & $23 \%$ & $0 \%$ & $100 \%$ \\
\hline Central & $77 \%$ & $8 \%$ & $11 \%$ & $4 \%$ & $100 \%$ \\
\hline
\end{tabular}

Fuente: elaboración propia con base en microdatos del Censo de Población de 1963. 
Figura 4. Dendrograma para la hipótesis 2 sobre fuerza de trabajo excedente Ocupación 1963: últimos agrupamientos (WARD)

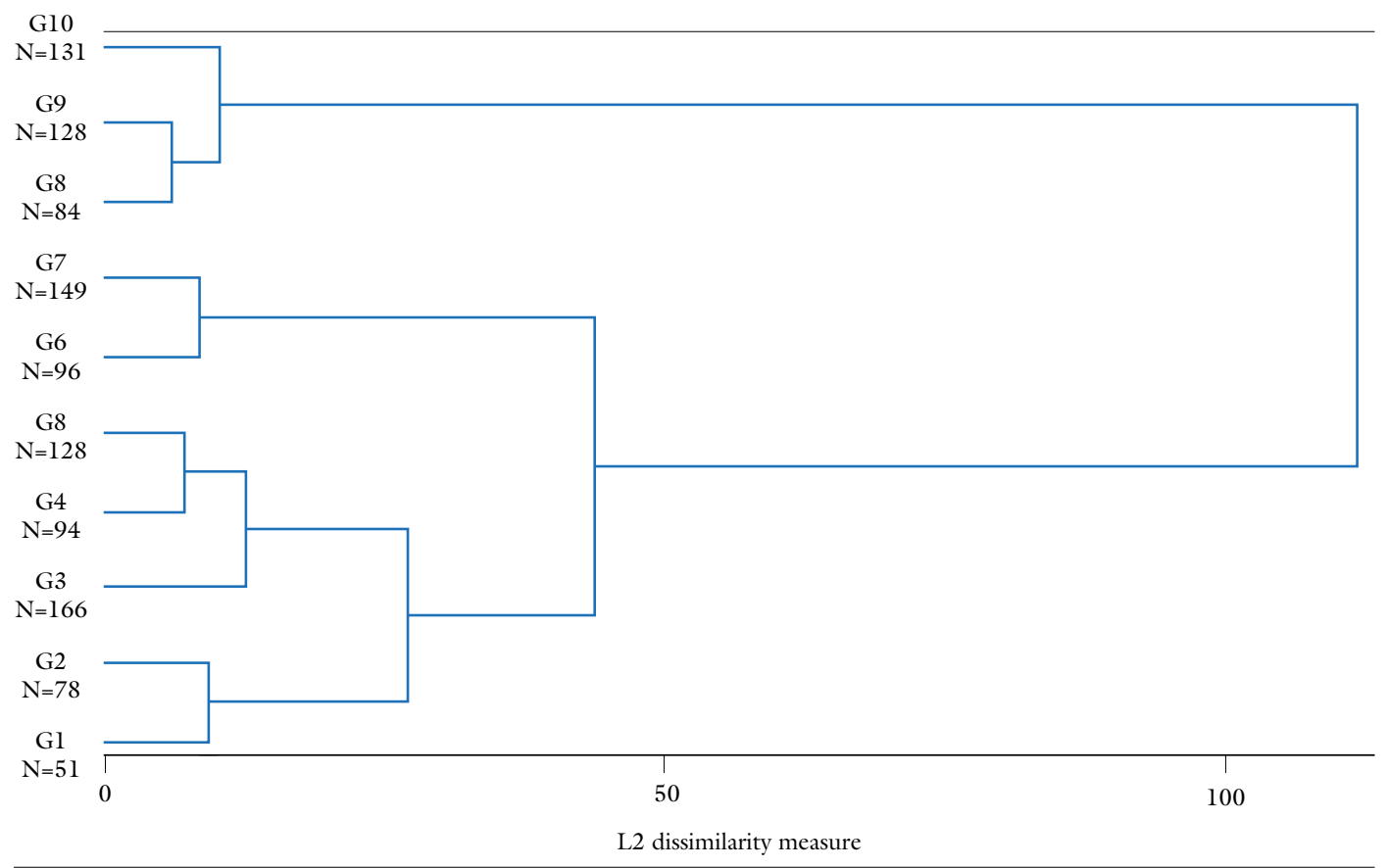

Fuente: elaboración propia con base en microdatos del Censo de Población de 1963.

Las localidades del Litoral y del suroeste predominan en el clúster 2 , zonas agroeconómicas 30,31 y 32 . La totalidad de las localidades del clúster 4 se concentran en la región Central. En el caso del clúster 5 , la región Noreste con $27 \%$ y la región central con $20 \%$ son preminentes.

En síntesis, este primer análisis parecería ser consistente con la teoría de la informalidad, aunque introduciendo un elemento cronológico importante: estas localidades informalmente establecidas, sin mínimas acciones de amanzanamiento ni mensura, se corresponden muy en especial con aquellas creadas en el siglo Xx. Son microlocalidades y además ubicadas sobre todo en las regiones del Noreste y de la región Central.

\section{Clúster con base en la teoría} del excedente de fuerza de trabajo

El análisis utiliza seis indicadores tomados del Censo 1963 sobre perfil laboral de los habitantes de la localidad. Diez no fueron incluidas al carecer de PEA.

Como se puede observar en la figura 4, conforme al criterio Calinski-Harabaz, 
${ }^{4}$ Si bien las pruebas $F$ son estadisticamente significativas, $P<0.01 \mathrm{en}$ todos los casos, las pruebas Bonferroni solo son significativas en $8,13 y$ 12 comparaciones.

5 Respectivamente, $F=298.27, \quad P<0.01 y$ $F=220.39, P<0.01$. En el primer caso, 19 de las 21 pruebas de Bonferroni informan diferencias significativas entre clústers con $P<0.05$. En el segundo caso, 15 de las 21 pruebas Bonferroni tuvieron $P<0.05$.

\section{tersitarias 46}

habría dos grandes agrupamientos polares de localidades: por un lado, los grupos de la parte inferior con 762 localidades y, por otro lado, los tres superiores con 343 localidades. El que se unan solo al último paso es informativo de la profundidad de las diferencias. El criterio DH sugiere nueve grupos; sin embargo, la solución de siete resulta también aceptable: es el siguiente valor DH más alto y tiene la cuarta menor $\mathrm{T}^{2}$. Esta solución es la que se retendrá.

La tabla 8 muestra que existe reducida variabilidad en la PEA, en ocupación como jornaleros y en desempleo juvenil. ${ }^{4}$ La que mayor diferencia marcada es la proporción de empleo agropecuario: mientras que en los grupos 6 y 7 tiene un máximo del $13 \%$, en los grupos 1 al 5 promedia el $55 \%$ (alcanzando un máximo del $74 \%$ en el clúster 5). La tasa de desocupación y el empleo en la industria tienen variaciones significativas ${ }^{5}$ entre los diferentes grupos, lo que permite también agregar a la comprensión de los grupos 6 y 7 (y eventualmente, también el 4) por contar con el más alto promedio de inserción laboral en el sector manufacturero, con

Tabla 8. Caracterización de los grupos de localidades para la hipótesis del excedente

\begin{tabular}{|l|c|c|c|c|c|c|c|}
\hline & $\mathbf{1}$ & $\mathbf{2}$ & $\mathbf{3}$ & $\mathbf{4}$ & $\mathbf{5}$ & $\mathbf{6}$ & 7 \\
\hline [1] Número de localidades & 51 & 78 & 166 & 222 & 245 & 212 & 131 \\
\hline [2] En cada clúster, proporción promedio de: & & & & & & & \\
\hline Pob. Econ. Activa & $36 \%$ & $31 \%$ & $38 \%$ & $34 \%$ & $40 \%$ & $39 \%$ & $38 \%$ \\
\hline Desocupados & $48 \%$ & $33 \%$ & $7 \%$ & $15 \%$ & $7 \%$ & $11 \%$ & $12 \%$ \\
\hline Desoc. Juvenil Mascul. & $7 \%$ & $4 \%$ & $1 \%$ & $2 \%$ & $1 \%$ & $2 \%$ & $2 \%$ \\
\hline Ocupados en el agro & $37 \%$ & $70 \%$ & $51 \%$ & $37 \%$ & $74 \%$ & $11 \%$ & $13 \%$ \\
\hline Ocupados como jornaleros & $1 \%$ & $0 \%$ & $1 \%$ & $1 \%$ & $0 \%$ & $3 \%$ & $2 \%$ \\
\hline Ocupados en la Industria & $4 \%$ & $3 \%$ & $5 \%$ & $8 \%$ & $3 \%$ & $9 \%$ & $28 \%$ \\
\hline Tamaños de localidad dentro de clústeres $(\%)$ & 1 & 2 & 3 & 4 & 5 & 6 & 7 \\
\hline Caseríos \& Poblados (hasta 299 hab.) & $96 \%$ & $96 \%$ & $93 \%$ & $76 \%$ & $96 \%$ & $57 \%$ & $38 \%$ \\
\hline Localidades (300al499) & $4 \%$ & $4 \%$ & $7 \%$ & $21 \%$ & $4 \%$ & $28 \%$ & $21 \%$ \\
\hline Pueblos \& Villas & $0 \%$ & $0 \%$ & $3 \%$ & $0 \%$ & $0 \%$ & $12 \%$ & $15 \%$ \\
\hline Ciudades & $0 \%$ & $0 \%$ & $0 \%$ & $0 \%$ & $0 \%$ & $3 \%$ & $26 \%$ \\
\hline Total & $100 \%$ & $100 \%$ & $100 \%$ & $100 \%$ & $100 \%$ & $100 \%$ & $100 \%$ \\
\hline
\end{tabular}

Fuente: elaboración propia con base en microdatos del Censo de 1963. 
Tabla 9. Distribución regional de los clústeres. Hipótesis del excedente

\begin{tabular}{|l|c|c|c|c|c|c|c|c|c|}
\hline \multicolumn{1}{|c|}{ Región (\%) } & $\mathbf{0}$ & $\mathbf{2}$ & $\mathbf{3}$ & $\mathbf{4}$ & $\mathbf{5}$ & $\mathbf{6}$ & $\mathbf{7}$ & Total & $\mathbf{N}$ \\
\hline Montevideo & $0 \%$ & $0 \%$ & $0 \%$ & $0 \%$ & $0 \%$ & $0 \%$ & $100 \%$ & $100 \%$ & 4 \\
\hline Canelones & $2 \%$ & $0 \%$ & $9 \%$ & $9 \%$ & $11 \%$ & $35 \%$ & $33 \%$ & $100 \%$ & 162 \\
\hline Suroeste & $1 \%$ & $1 \%$ & $20 \%$ & $19 \%$ & $19 \%$ & $21 \%$ & $19 \%$ & $100 \%$ & 135 \\
\hline Litoral & $3 \%$ & $8 \%$ & $13 \%$ & $24 \%$ & $23 \%$ & $15 \%$ & $13 \%$ & $100 \%$ & 194 \\
\hline Noreste & $7 \%$ & $17 \%$ & $16 \%$ & $22 \%$ & $25 \%$ & $10 \%$ & $2 \%$ & $100 \%$ & 243 \\
\hline Merin & $3 \%$ & $8 \%$ & $15 \%$ & $24 \%$ & $39 \%$ & $9 \%$ & $3 \%$ & $100 \%$ & 75 \\
\hline Este & $1 \%$ & $1 \%$ & $19 \%$ & $18 \%$ & $17 \%$ & $35 \%$ & $8 \%$ & $100 \%$ & 88 \\
\hline Central & $9 \%$ & $6 \%$ & $15 \%$ & $23 \%$ & $25 \%$ & $17 \%$ & $4 \%$ & $100 \%$ & 204 \\
\hline
\end{tabular}

Fuente: elaboración propia con base en microdatos del Censo de 1963.

desempleos entre el $11 \%$ y el $14 \%$. En cambio, carecen de peso discriminador entre grupos las variables de tasa de actividad, desocupación juvenil y empleo como jornaleros.

El tipo de localidad que se aproxima más a la hipótesis del excedente agrario es el clúster 1. Su población se caracteriza por un muy alto nivel de desocupación $(48 \%)$; la participación en actividades agropecuarias está en el mínimo dentro de esa rama del dendrograma $(37 \%)$ y las actividades de jornaleros y demás no tienen mayor relevancia. Este clúster reúne a 51 localidades en total y se emparenta con el clúster 2 (por la alta desocupación), pero con la diferencia en la alta participación del agro. Es decir, podríamos interpretar gruesamente que, reuniendo estos dos grupos de localidades, junto con los grupos 3 y 5 representan formas diferentes de articulación entre la producción rural y la microurbanización. Esto se observa en la tabla 9. Los cuatro grupos de localidades referidos son caseríos y poblados (menos de 300 habitantes) y contrastan con el peso que tienen las ciudades en el grupo 7 .

La tabla 9 muestra cómo se distribuyen los grupos dentro de las regiones. El tipo 7 de localidad predomina de nuevo en el sur, suroeste y litoral, en estas dos últimas regiones también se presenta una gran proporción de las localidades de tipo 6. En el noreste predominan las localidades del grupo 5 , pero debe observarse que una de cada cuatro es de tipo 1 o 2 . Esto se observa también la región central.

En síntesis, la teoría del excedente de fuerza de trabajo agropecuaria parecería no tener un asidero robusto a nivel nacional, aunque sí muestra mayor plausibilidad cuando se analizan dos regiones 
${ }^{6}$ Tal como se puede apreciar, en la figura 5, el árbol muestra dos grandes ramas a partir de los valores de distancia de Gower superiores a 40, una de las cuales se fusiona a valores superiores a 35. El indice CH indica como óptimo 4 grupos $(\mathrm{CH}=912.67)$ en tanto que en las pruebas de DH esa solución es la cuarta recomendada. Sin embargo, las tres primeras consistirian en 14, 12 y 8 grupos respectivamente. Aplicando el criterio, se retienen 4 grupos.

\section{territarias 46} 22

Figura 5. Dendrograma para la hipótesis 3 sobre segregación

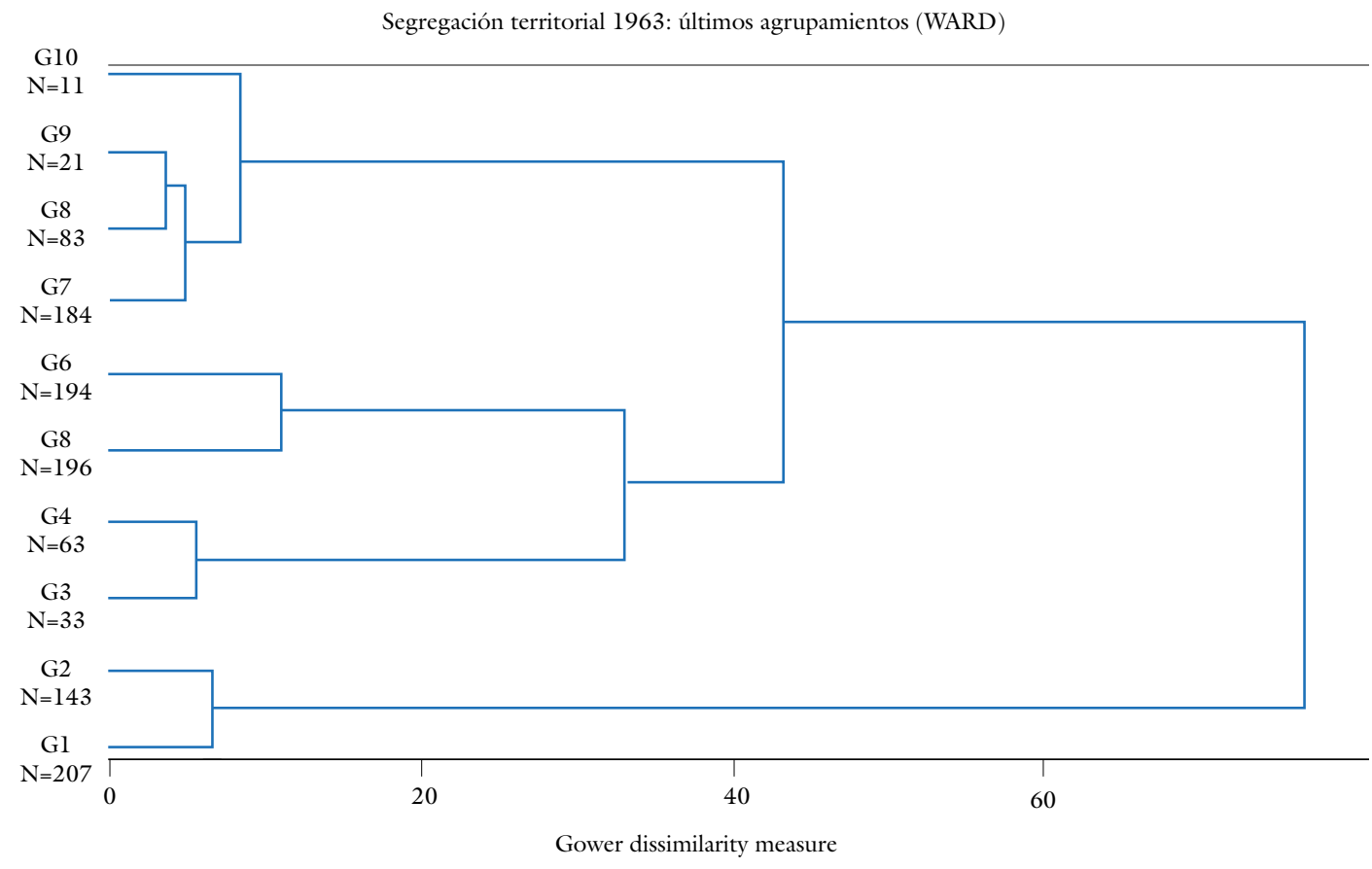

Fuente: elaboración propia con base en microdatos del Censo de Población de 1963.

económicas, la Noreste y la Central, por aquellos años predominantemente ganaderas.

\section{Clúster con base en la teoría de la segregación residencial}

El análisis de la teoría de la segregación residencial se hará con base en información sobre la infraestructura habitacional predominante en la localidad, aportada por el Censo de 1963. Se utilizarán tres indicadores relativos a la calidad de los materiales del piso, la pared y el techo. Se agrega un indicador jurídico (ocupación de la vivienda sin justo título) y ubicación conurbana de la localidad. Entendemos que esta es una medida muy restrictiva de aquel concepto de segregación, por tanto, los hallazgos han de interpretarse con cautela.

Como se puede observar en la tabla 10 , con base en el criterio $\mathrm{CH}$, se tomaron cuatro grupos para unir a las localidades, según la teoría de la segregación residencial. ${ }^{6}$

Las variables de carencias infraestructurales incrementan sus valores entre el 
Tabla 10. Caracterización de los grupos de localidades para la hipótesis de la segregación

\begin{tabular}{|c|c|c|c|c|}
\hline & 1 & 2 & 3 & 4 \\
\hline $\begin{array}{l}\text { Número de } \\
\text { localidades }\end{array}$ & 325 & 345 & 113 & 342 \\
\hline \multicolumn{5}{|l|}{$\begin{array}{l}\text { Dentro de cada } \\
\text { clúster }(\%)\end{array}$} \\
\hline Localidad Conurbada & $1 \%$ & $0 \%$ & $100 \%$ & $0 \%$ \\
\hline $\begin{array}{l}\% \text { vivienda Paredes } \\
\text { ligeras / desechos }\end{array}$ & $77 \%$ & $42 \%$ & $26 \%$ & $13 \%$ \\
\hline $\begin{array}{l}\% \text { vivienda Techos } \\
\text { ligeros / desechos }\end{array}$ & $83 \%$ & $57 \%$ & $48 \%$ & $25 \%$ \\
\hline $\begin{array}{l}\% \text { vivienda Pisos } \\
\text { tierra, escombros }\end{array}$ & $86 \%$ & $55 \%$ & $42 \%$ & $16 \%$ \\
\hline $\begin{array}{l}\% \text { vivienda Tenencia } \\
\text { precariat }\end{array}$ & $15 \%$ & $4 \%$ & $7 \%$ & $3 \%$ \\
\hline \multicolumn{5}{|l|}{$\begin{array}{l}\text { Dentro de cada } \\
\text { clúster }(\%)\end{array}$} \\
\hline $\begin{array}{l}\text { Caseríos \& Poblados } \\
\text { (hasta } 299 \text { hab.) }\end{array}$ & $95 \%$ & $81 \%$ & $63 \%$ & $62 \%$ \\
\hline $\begin{array}{l}\text { Localidades ( } 300 \\
\text { a } 1499 \text { hab.) }\end{array}$ & $5 \%$ & $16 \%$ & $19 \%$ & $20 \%$ \\
\hline Pueblos \& Villas & $0 \%$ & $3 \%$ & $4 \%$ & $11 \%$ \\
\hline Ciudades & $0 \%$ & $0 \%$ & $15 \%$ & $7 \%$ \\
\hline Total & $100 \%$ & $100 \%$ & $100 \%$ & $100 \%$ \\
\hline
\end{tabular}

Fuente: elaboración propia con base en Censo de 1963.

grupo 1 y el grupo 4. En el grupo 1, aglomera localidades donde al menos tres de cada cuatro viviendas tienen techos ligeros, paredes livianas y/o pisos de tierra o escombros. En el grupo 2 se observa un patrón semejante, pero con mayor heterogeneidad. El grupo 4 reúne localidades con viviendas en las que las carencias son minoritarias. Se observa que el material de los techos, así como la titularidad jurídica tienen menor peso discriminatorio. Esto a pesar de que en el grupo 1 hay cinco veces menos viviendas con títulos irregulares.

El grupo 4 agrupa a las localidades más grandes: está integrado por todas las ciudades y 10 de las 12 villas reconocidas como tales en 1963, aunque la mayoría se trata de poblados y caseríos. El contraste se observa en el grupo 1 donde la totalidad de las localidades tienen menos de 300 habitantes. Claramente, estas son los rancheríos. Solo el grupo 3 tiene localidades conurbadas y responde a la presencia de 17 de las capitales.

La distribución de los grupos de localidades según región (tabla 11) reitera dos cosas importantes. Por un lado, al observar los extremos, contrasta el Noreste con el Gran Canelones y el Suroeste. Mientras que, en aquella, el $57 \%$ de localidades se catalogan como rancheríos, en las segundas es menos del 5\%. En el otro extremo, en estas dos regiones, al menos la mitad de las localidades puede denominarse como consolidadas. Pero, por otro lado, es importante destacar los rezagos edilicios que parecerían ser la característica predominante de las localidades en todas las regiones, excepto en el Gran Canelones. 
Tabla 11. Distribución de las localidades según región para la hipótesis de la segregación

\begin{tabular}{|l|c|c|c|c|c|}
\hline Región (\%) & $\mathbf{1}$ & $\mathbf{2}$ & $\mathbf{3}$ & $\mathbf{4}$ & Total \\
\hline Montevideo & $0 \%$ & $0 \%$ & $75 \%$ & $25 \%$ & $100 \%$ \\
\hline Canelones & $4 \%$ & $21 \%$ & $4 \%$ & $72 \%$ & $100 \%$ \\
\hline Suroeste & $5 \%$ & $29 \%$ & $11 \%$ & $55 \%$ & $100 \%$ \\
\hline Litoral & $29 \%$ & $37 \%$ & $11 \%$ & $23 \%$ & $100 \%$ \\
\hline Noreste & $57 \%$ & $25 \%$ & $14 \%$ & $3 \%$ & $100 \%$ \\
\hline Merin & $37 \%$ & $33 \%$ & $12 \%$ & $17 \%$ & $100 \%$ \\
\hline Este & $11 \%$ & $39 \%$ & $13 \%$ & $36 \%$ & $100 \%$ \\
\hline Central & $38 \%$ & $38 \%$ & $5 \%$ & $19 \%$ & $100 \%$ \\
\hline
\end{tabular}

Fuente: elaboración propia con base en Censo de 1963.

\section{Discusión de hipótesis}

¿Son exhaustivas, contradictorias o complementarias las hipótesis sobre la microurbanización? Esta sección discute nuestra primera hipótesis, analizando la asociación entre las tres clasificaciones mediante coeficientes de asociación $\mathrm{V}$ de Cramer (Cortés \& Rubalcava, 1987), siendo analizado en la tabla 12. La magnitud computada resulta solo moderada, lo que permite en principio descartar la idea de que tales teorías sean contradictorias y aceptar la más razonable hipótesis de que haya complementariedad, aunque con limitaciones.

La hipótesis que destaca la omisión reguladora del Estado en el ordenamiento territorial es más que plausible. El poblamiento fue sobre todo en la primera mitad del siglo $\mathrm{Xx}$, un proceso predominantemente informal. Hubo ausencia estatal tanto en la fundación como la oficialización, incluso la tardía Ley de 1946 no modificó mayormente esta situación.

Tabla 12. Estadísticos de asociación $\mathrm{v}$ de Cramer para el tamaño de la localidad, la región socioeconómica y las tres clasificaciones por análisis de clúster

\begin{tabular}{|c|c|c|c|c|c|}
\hline & 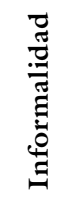 & 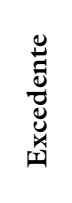 & 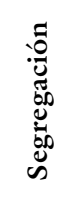 & تُ & 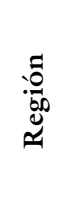 \\
\hline Informalidad & 1.00 & & & & \\
\hline Excente & 0.34 & 1.00 & & & \\
\hline Segregación & 0.25 & 0.37 & 1.00 & & \\
\hline Tamaño & 0.45 & 0.35 & 0.23 & 1.00 & \\
\hline Region & 0.23 & 0.22 & 0.35 & 0.15 & 1.00 \\
\hline
\end{tabular}

Fuente: elaboración propia con base en Censo de 1963.

Pero la informalidad urbana no está restringida al excedente de fuerza de trabajo rural. Para 1963, solo el 15\% de aquellas eran también localidades con alta desocupación y empleo agrícola a la vez (grupo 1 y 2 de la hipótesis de excedente), y por tanto asociables al fenómeno de la modernización rural.

A su vez, la hipótesis del excedente no explica la precariedad. Solo una pequeña parte $(16 \%)$ de las localidades, aquí clasificadas como precarias infraestructuralmente y no conurbadas (grupos 1 y 2 en la hipótesis de segregación), constituyen 
localidades excedentarias en el sentido anterior (grupos 1 y 2 ). El $35 \%$ de estas se corresponde con localidades donde la desocupación es bastante más baja (grupos 4,6 y 7). Es decir, que parecería ser que las microlocalidades no han sido generadas por la modernización rural más que por la segregación urbana.

En síntesis, ¿cuáles serían aquellas localidades de tan particular estructura, tematizadas por la bibliografía como rancheríos rurales? Tal como fuimos indicando en cada clasificación, hubo un grupo que (al menos) se aproximó a aquella caracterización. La intersección entre estas categorías conforma un grupo de 85 localidades que serían a la vez informales, establecidas luego de 1908, con alta desocupación y baja dedicación al agro, y con infraestructura habitacional predominantemente precaria. Esto representa menos del 10\% de los caseríos y centros poblados de 1963. Las restantes localidades tienen solo algunas características (pero no otras) y aparentemente responderían a otras situaciones. Examinado este tipo tan particular, se encuentra con mayor peso en la región Noreste (18\%) y en la Central (13\%), siendo prácticamente inexistente en el Gran Canelones, en el Suroeste o en el Este.

\section{Conclusiones}

En 1963 Uruguay presentaba una estructura de localidades con un importante nivel de heterogeneidad, catalogada con tres hipótesis de la época para describir la emergencia de los rancheríos.

Esto permitiría descartar que la generalidad de los pobladores $y$, por lo tanto, el poblado, formaran una masa "excedente de desocupados e improductivos" como era denominado en su momento. La reducida proporción de localidades realmente "excedentarias" hace pensar que son territorios urbanos segregados, donde comienza a asentarse un "ejército agrario de reserva" que alterna entre tareas estacionales agrarias y manufacturas. Esta fue la tesis esbozada en 1955 ( $\mathrm{Pi} \mathrm{Hu}-$ garte \& Wettstein, 1955) y sistematizada en 1960 (Rama, 1960).

La ausencia del Estado habría propiciado no solo la informalidad urbana, sino una desigual distribución del bienestar, como señalan Chiarino y Saralegui (1944) y luego por CLAEH-CINAM (1963). En estas localidades, las familias debían costearse la electricidad, el agua potable, el drenaje y la atención de salud.

El proto-estado de bienestar o estado bienestar estratificado del Uruguay de los sesenta parece haberse establecido solo en las 79 localidades formales, que cuentan con mercados de trabajo diversificados y mayores niveles, en promedio, de infraestructura habitacional. Por lo tanto, cabe preguntarse si esta segmentación territorial del bienestar de la primera mitad del Siglo xx no fue un factor causal que incentivó el éxodo a las ciudades y abandono de las pequeñas localidades, observado por diversos censos a partir de 
la década del setenta. Este es un ejercicio pendiente y que encuadra en el enfoque de analizar las desigualdades sociales bajo la lupa de la larga duración.

\section{Referencias}

Alonso, R., \& Demasi, C. (1986). Uruguay 1958-1968. Crisis y estancamiento. Banda Oriental.

Álvarez Lenzi, R. (1986). Fundación de centros poblados en el Uruguay. Facultad de Arquitectura, Universidad de la República.

Bértola, L., \& Bittencourt, G. (2015). Un balance histórico de la industria uruguaya: entre el "destino manifiesto" y el voluntarismo. Facultad de Ciencias Sociales; Universidad de la República; Ministerio de Industria, Energía y Minería.

Brena, T. (1936). La Unión Cívica y el problema del proletariado rural. El bien público.

Chiarino, J. V., \& Saralegui, M. (1944). Detrás de la ciudad. Ensayo de sintesis de los olvidados problemas campesinos. Impresora Uruguaya $S$. A.

CLAEH-CINAM. (1963). Situación económica y social del Uruguay Rural. Centro Latino Americano de Economía Humana (CLAEH); Ministerio de Ganadería, Presidencia de la República.

Cortés, F., \& Rubalcava, R. M. (1987). Métodos estadísticos aplicados a la in-

\section{territarias 46} 26 de asociación. El Colegio de México.
Davrieux, A. (1972). Indice toponímico de lugares poblados del Uruguay. Dirección General de Estadística, Presidencia de la República.

DGEyC. (1965). Distribución territorial de la población y la vivienda. Departamento de Durazno. IV Censo General de Población y II de Vivienda. 16 de octubre de 1963. Dirección General de Estadística y Censo, Ministerio de Hacienda, Presidencia de la República. DGEyC. (1989). Índice toponímico de entidades de población: VI censo de población, IV censo de viviendas 1985. Dirección General de Estadística y Censos, Presidencia de la República.

Everitt, B., Landau, S., Leese, M., \& Stahl, D. (2011). Cluster analysis ( $5^{\mathrm{a}} \mathrm{ed}$.). John Willey \& Son.

Fernández, T. (2001). El proceso histórico de regionalización en Uruguay (17001950). Centro de Estudios Sociológicos, El Colegio de México.

Fernández, T. (2002). Cambios en la estructura agraria de Uruguay entre 1951 y 2000. Estudios Sociológicos, $X X(2), 384-424$. https://www.jstor. org/stable/40420740

Fernández, T. (2010). Evolución de la pobreza multidimensional en Montevideo (2006-2009). En Departamento de Sociología-FCS, El Uruguay desde la Sociologia (Tomo VIII, pp. 95-117). Departamento de Sociología, UDELAR.

Fernández, T. (2018). La conformación histórica de las regiones en Uruguay 
(1730-1990). Un ensayo de sintesis desde la sociología histórica [Primer documento de trabajo del proyecto de investigación "Territorio y desigualdades educativas"]. https:// www.researchgate.net/figure/Fuente-Travieso-2017-mapa-1-pp-34 figl_332728788

Fernández, T., \& Ríos, A. (2013). Implicancias para la politica educativa de las tendencias socioeconómicas $y$ educativas registradas en el espacio regional "Frontera-Nordeste" de Uruguay. Departamento de Sociología, Facultad de Ciencias Sociales; Centro Universitario de Rivera; Universidad de la República.

Fernández, T., \& Wilkins, A. (2019). Procesos de configuración regional y localidades de Uruguay 1900-1960. Iberoamerica, 21(1), 159-206.

Galván, E., Moreira, C., \& Vázquez, D. (2012, noviembre). La CIDE como invitación a repensar el Uruguay en el contexto de las estrategias de desarrollo de la posguerra. Revista Uruguaya de historia económica, II(2), 75-84. http://www.audhe.org.uy/ images/stories/upload/Revista/ Revista_N_2/galvan\%20et\%20al\%20 cide $\% 20$ como\%20invitacion.pdf

García Acevedo, D. (1967). Informe producido ante el Congreso Rural Anual de 1910. Comisión de Estudios para mejorar la situación de la gente pobre de la Campaña. Asociación Rural del Uruguay [Sección Historia de la
Cultura. Fuentes para la Historial Social y Económica del Río de la Plata N. ${ }^{\circ}$ 1]. Facultad de Humanidades y Ciencias. Universidad de la República. García Alonso, M., \& Scagliola, G. (2012). Misiones socio-pedagógicas 1945-1971. Consejo de Formación en Educación, Administración Nacional de Educación Pública.

Halpin, B. (2016). Cluster Analysis Stopping rules with Stata [Working Papers WP2016-01]. Department of Sociology, University of Limerick. http:// ulsites.ul.ie/sociology/sites/default/ files/wp2016-01.pdf

Icaza Dufour, F. (Coord.). (1987). Recopilación de leyes de los reynos de las Indias [Estudios histórico-jurídicos]. Fondo para la difusión del Derecho. https:// www.colmich.edu.mx/files/ceh/rdiego/publicaciones/pdf/077_RecopilacionLeyesReynosIndias.pdf

INE. (2008). Toponimia y categorización juridica oficial de localidades urbanas del Uruguay. Instituto Nacional de Estadística, Presidencia de la República.

INE. (2018). Listado de Localidades según censos. http://www.ine. gub.uy/c/document_library/get_ file? uuid $=220 \mathrm{c} 14 \mathrm{ae}-7 \mathrm{~d} 92-4737-8 \mathrm{e} 9 \mathrm{~d}-$ 9bb2991c40f1\&groupId = 10181

Klaczko, J. (1981). El Uruguay de 1908: su contexto urbano-rural, antecedentes y perspectivas [Cuaderno N. ${ }^{\circ} 42$ ]. CIESU.

López Lomba, R. (1909). Anuario Estadístico de la República Oriental del territarias 46 
Uruguay. Censo general de la República en 1908. Dirección General de Estadística, Ministerio de Hacienda, Presidencia de la República.

Marcheschi, A., Markarian, V., \& Yaffé, J. (2015). Claves del período. En G. Caetano, A. Marcheschi, V. Markarian, \& J. Yaffé, Uruguay: el "pais modelo" ysu crisis 1930-2010 (pp. 15-36). MAPFRE; Planeta.

Martínez Lamas, J. (1930). Riqueza y pobreza del Uruguay. El Palacio del Libro.

Martorelli, H. (1969). La sociedad urbana. Nuestra Tierra.

Panizza, F. (1990). Uruguay: Batllismo y después. Pacheco, militares y tupamaros en la crisis del Uruguay Batllista. Banda Oriental.

Pi Hugarte, R., \& Wettstein, G. (1955). Rancheríos rurales y rancheríos suburbanos. Revista del Centro de Estudiantes de Derecho, (84), 173.

Rama, C. M. (1959). De la singularidad de la urbanización en Uruguay. Seminario sobre problemas de urbanización en América Latina, sala de conferencias N. ${ }^{\circ}$ 6. Santiago de Chile.

Rama, C. M. (1960). Las clases sociales en el Uruguay. Estructura y morfología. Nuestro Tiempo.

Rial, J. (1980). Estadisticas históricas de Uruguay 1850-1930. Población, producción agropecuaria, comercio, industria, urbanización, comunicaciones y calidad de vida. [Cuaderno N. ${ }^{\circ} 40$ ]. Centro de Informaciones y Estudios del Uruguay (CIESU).

Solari, A. (1954). Sociología rural nacional. Facultad de Derecho, Universidad de la República.

Terra, J. P. (1969). La vivienda. Colección Nuestra Tierra.

DGO. (1877). Reglamento para el trazado de nuevos pueblos y colonias en el territorio nacional. Dirección General de Obra; Ministerio de Hacienda; Imprenta Nacional de Montevideo.

Wettstein, G., \& Rudolf, J. (1969). La Sociedad Rural [Número 16]. Colección Nuestra Tierra. 